\title{
MAHÂRAH AL-KITÂBAH BAGI MAHASISWA MELALUI UPDATE STATUS PADA MEDIA WHATSAPP
}

\author{
Halimatus Sa diyah \\ (halimamaliem@gmail.com) \\ (Dosen PKPBA UIN Maulana Malik Ibrahim Malang)
}

\begin{abstract}
المللخص
إن الكتابة باللغة العربية ليست سهلة لغير الناطقين بها، كذلك لطلبة الإندونيسيا. يواجه الطلبة الصعوبات في كتابة العربية بوجود الفرق بين العربية والإندونيسية من ناحية الشكل و الإجراءات لترتيب الجمل. لذلك، يحتاج طلبة الإندونيسيا إلى ممارسـة مستمرة و تطبيق مستمر ليكونوا ماهربن في كتابة العربية. وقد تطور التكولوجيا في هذا العصر الذي يكون أحد الحلول من هذه المشكلة. ووسيلة واتسأب من وسـائل الرقمية مستخدمة لتحسين وتطوبر كتابة العربية عند الطلبـة. وكل شخص لاسيما طالب يعمل تحديث الحالة (Update Status) كنشاط باستخدام وسيلة واتساب. إذا، باستخدام وسيلة مشهورة عند الطلبة مثل واتسأب وبنشاط تحديث الحالة في واتسأب سيساعد الطلبـة في ترقية مهارة كتابة العريية. الكلمات الرئيسية: مهارة الكتابة؛ وسيلة واتسأب؛ تحديث الحالة
\end{abstract}

Menulis dalam Bahasa Arab tidak mudah dilakukan bagi non Arab, begitu pula mahasiswa Indonesia. Mahasiswa mengalami kesulitan untuk menulis Bahasa Arab dikarenakan adanya perbedaan antara Bahasa Arab dan Bahasa Indonesia, baik dari segi bentuk dan cara merangkai kalimat. Oleh karena itu, mahasiswa Indonesia membutuhkan latihan dan praktik yang kontinyu agar menjadi terampil dalam menulis dalam Bahasa Arab. Teknologi pada zaman sekarang telah mengalami perkembangan yang dapat menjadi salah satu solusi dari problematika di atas. Media whatsapp adalah salah satu media digital yang dipergunakan untuk memperbaiki dan mengembangkan tulisan Bahasa Arab mahasiswa. Setiap orang, termasuk mahasiswa melakukan update status sebagai kegiatan dalam menggunakan media whatsapp. Sehingga, dengan menggunakan media yang familiar dikalangan mahasiswa seperti whatsapp dan dengan melakukan kegiatan update status di whatsapp, maka dapat membantu mahasiswa dalam meningkatkan keterampilan menulis dengan Bahasa Arab.

Kata Kunci: Mahârah al-Kitâbah; Media Whatsapp; Update Status. 


\section{A. PENDAHULUAN}

Seiring dengan perkembangan zaman, kita tidak hanya dituntut mahir dalam berbahasa Indonesia saja, akan tetapi juga perlu dikenalkan dengan bahasa- bahasa asing lainnya, seperti Bahasa Arab. Bahasa Arab merupakan bahasa pengantar internasional yang sangat penting. Karena Negara Indonesia merupakan bagian dari negara-negara yang ada di dunia, oleh karenanya jika bangsa Indonesia ingin maju dan berkembang, maka harus dapat berinteraksi di bidang politik, ekonomi, sosial, budaya, pertahanan, keamanan, dan pendidikan dengan berbagai negara di dunia melalui perantara bahasa internasional yang salah satu diantaranya adalah Bahasa Arab.

Bahasa Arab merupakan salah satu bahasa internasional. Pada tahun 1973 untuk pertama kalinya bahasa Arab dijadikan bahasa resmi dalam lingkungan Perserikatan Bangsa-Bangsa (PBB). Pidato-pidato, pembicaraan dan perdebatan di forum PBB diterjemahkan ke dalam bahasa Arab sejajar dengan bahasa-bahasa asing lainnya. Pemakian bahasa Arab sebagai salah satu bahasa resmi di PBB menempatkan bahasa Arab sebagai salah satu alat komunikasi dalam hubungan diplomasi internasional. ${ }^{1}$

Bahasa Arab dalam pandangan pemerintah adalah bahasa asing. Hal ini terbukti, misalnya, dalam peraturan pemerintah Menteri Agama RI nomor 2 tahun 2008 tentang Standar Kompetensi dan Standar Pendidikan Agama Islam dan Bahasa Arab. Dalam peraturan tersebut dikatakan bahwa Tujuan mata pelajaran bahasa Arab ialah: mengembangkan kemampuan berkomunikasi bahasa Arab, baik lisan maupun tulis, yang mencakup empat kecakapan berbahasa, yakni menyimak (istima'), berbicara (kalam), membaca (qira'ah), dan menulis (kitabah). ${ }^{2}$

Menumbuhkan kesadaran tentang pentingnya Bahasa Arab sebagai salah satu bahasa asing untuk menjadi alat utama belajar, khususnya dalam mengkaji sumber-sumber ajaran Islam dan mengembangkan pemahaman tentang saling keterkaitannya antara bahasa dan budaya serta memperluas cakrawala budaya. Dengan demikian peserta didik diharapkan memiliki wawasan lintas budaya dan melibatkan diri dalam keragaman budaya. ${ }^{3}$

\footnotetext{
${ }^{1}$ Acep Hermawan,"Metodelogi Pembelajaran Bahasa Arab", Bandung: Rosda, 2011, 87

${ }^{2}$ Ibid., 32.

${ }^{3}$ Hermawan, Metodologi Pembelajaran ..............., 57.
} 
Pembelajaran dilihat dari ruang lingkupnya terdiri dari beberapa komponen. Komponen tersebut meliputi tujuan, bahan pelajaran, kegiatan belajar mengajar, metode, alat, sumber belajar atau evaluasi. Semua komponen tersebut harus saling berkaitan satu sama lain untuk mencapai keberhasilan pendidikan sesuai dengan tujuan yang diinginkan. Keberhasilan suatu proses pembelajaran tidak dapat terlepas dari peran media didalamnya, sebab alat atau media pendidikan merupakan suatu bagian integral dari proses pendidikan di Sekolah. ${ }^{4}$

Bahasa Arab sebagai bahasa asing menempati posisi penting di Indonesia, khususnya bagi umat Islam, tidak lain karena kedudukan bahasa Arab sebagai bahasa agama umat Islam. Bahasa Arab adalah bahasa AlQur'an dan Al Hadis, yang mana keduanya adalah landasan dasar agama Islam, serta bahasa bagi kebudayaan Islam seperti filsafat, ilmu kalam, ilmu hadis, tafsir dan lain sebagainya. Bangsa yang maju adalah bangsa yang peduli akan nasib generasi penerusnya, sedangkan bahasa merupakan kunci utama bagi generasi bangsa untuk membuka jendela dunia. Maka sebaiknya generasi penerus bangsa, perlu dikenalkan dan diajarkan Bahasa Arab. Adapun salah satu cara dalam mengenalkan Bahasa Arab kepada khalayak adalah dengan belajar dan pembelajaran.

Jenjang belajar di kampus adalah pengalaman pembelajaran yang berbeda dari pada di jenjang sekolah. Di kampus, mahasiswa dituntut untuk lebih mandiri dan mendapatkan pengalaman pembelajaran yang mendalam. Pembelajaran bahasa asing merupakan bagian dari upaya membekali mahasiswa untuk siap menghadapi tantangan yang ada di masyarakat kelak. ${ }^{5}$

Di Universitas Islam, Bahasa Arab menjadi bahasa penting untuk diberikan kepada mahasiswa. Hal ini dilakukan untuk memberikan pengalaman dan keistimewaan yang menjadi bekal dalam kehidupan mahasiswa di masa mendatang. Mahasiswa yang memiliki keterampilan dalam bahasa asing akan lebih siap dalam menghadapi persaingan global yang semakin ketat.

${ }^{4}$ Oemar Hamalik, Media Pendidikan, Bandung: PT.Citra Andily Bakti, 1989, 1.

5 Sa`diyah, H. Upaya Menumbuhkan Self-Confidence Berbicara Bahasa Arab Mahasiswa Melalui Grup Whatsapp. Al Mi'yar: Jurnal Ilmiah Pembelajaran Bahasa Arab dan Kebahasaaraban, 2(2), 149. https://doi.org/10.35931/am.v2i2.119 (2019). 
Dewasa ini kecenderungan pembelajaran yang kurang menarik merupakan hal yang wajar yang dialami oleh guru, yang mana mereka tidak memahami kebutuhan dari siswanya baik dalam karakteristik, maupun dalam pengembangan ilmu dari suatu materi yang dipelajari.Setiap materi pelajaran tentu memiliki tingkat kesukaran yang bervariasi. Pada satu sisi ada bahan pelajaran yang tidak memerlukan alat bantu, tetapi dilain pihak ada bahan pelajaran yang sangat memerlukan alat bantu berupa media pengajaran. Karena bahan yang tinggi sukar diproses oleh anak didik, apalagi bagi anak didik yang kurang menyukai bahan pelajaran yang disampaikan oleh guru. Maka dari itu, media sebagai alat bantu dalam proses belajar mengajar adalah suatu kenyataan yang tidak dapat dipungkiri.

Edgar Dale telah mengklasifikasikan beberapa sumber belajar yang kemudian menjadi pengalaman belajar menurut tingkatannya yaitu dari yang paling kongkrit ke yang paling abstrak sebagai usaha memanfaatkan media sebagai alat bantu. ${ }^{6}$ Dosen memberikan pembelajaran menggunakan media pembelajaran yang dapat membantu tercapainya tujuan pembelajaran. Begitu pula ynag dilakukan oleh dosen pengajar Bahasa Arab yang senantiasa melakukan pemilihan media pembelajaran yang menarik bagi mahasiswa.

Pembelajaran menulis Bahasa Arab (Mahârah al-Kitâbah) bagi mahasiswa non Arab bukanlah hal yang mudah. Untuk menjad terampil, mahasiswa membutuhkan latihan yang dilakukan secara terus-menerus. Pada zaman digital yang tanpa batas, seperti saat ini, maka pembelajaran Bahasa Arab sangat terbantu dengan fasilitas media digital tersebut.

Inovasi dan kreatifitas dosen Bahasa Arab senantiasa dilakukan. Salah satunya adalah dengan memanfaatkan media digital dalam mengajarkan Bahasa Arab, termasuk Mahârah al-kitâbah . Media whatsapp sebagai salah satu media digital yang familiar di kalangan mahasiswa dan update status menjadi bagian yang lekat dengan whatsapp.

Sehingga, dalam tulisan ini, penulis memaparkan beberapa hal yang terkait dengan Mahârah al-kitâbah bagi mahasiswa melalui update status pada media whatsapp. Untuk mendapatkan deskripsi yang jelas, penulis

${ }^{6}$ Sadat, A. (2017). LINGKUNGA BAHASA SEBAGAI MEDIA PEMBELAJARAN BAHASA ARAB (Ikhtiar membangun Pembelajaran Yang Efektif dan Produktif). AL-AF'IDAH: Jurnal Pendidikan Bahasa Arab dan Pengajarannya, 1(1), 7. 
membatasi tulisan berdasarkan rumusan masalah, yaitu: Pertama; Apa itu mahârah al-kitâbah bagi mahasiswa? Kedua; Apa itu update status pada media whatsapp? Ketiga; Bagaimana implementasi Mahârah al-kitâbah bagi mahasiswa melalui update status pada media whatsapp?

\section{B. Mahârah al-Kitâbah Bagi Mahasiswa}

Belajar disiplin ilmu apapun membutuhkan latihan dan pengalaman agar terjadi perubahan perilaku. ${ }^{7}$ Begitu pula dengan belajar Bahasa Arab, termasuk Mahârah al-kitâbah. Mahârah al-kitâbah atau keterampilan menulis menjadi bagian terakhir dari empat keterampilan Bahasa Arab yang diajarkan, bahkan dianggap menjadi keterampilan yang paling sulit. Sehingga, bagi mahasiswa mon-Arab untuk mencapai tahap terampil, maka al-kitâbah membutuhkan latihan dan praktek yang kontinyu. ${ }^{8}$

Mahârah al-kitâbah secara bahasa artinya adalah keterampilan menulis, sedangkan secara istilah adalah bagian dari keterampilan bahasa tertulis dan dijadikan sebagai sarana komunikasi tanpa batas ruang dan waktu. ${ }^{9}$ Mahârah al-kitâbah berarti terampil untuk mendeskripsikan ide dan pikiran secara tertulis yang dimulai dengan merangkai kata hingga membuat karangan secara tertulis. ${ }^{10}$ Sehingga, pemilihan diksi yang tepat dan penyusunan kalimat yang sesuai dengan kaidah Bahasa Arab tetap menjadi perhatian.

Penyampaian ide dan gagasan dapat dilakukan dengan al-kitâbah secara sistematis. Agar al-kitâbah dapat dipahami oleh orang lain, maka dibutuhkan latihan menyusun kata, kalimat hingga paraghraph, memiliki kekayaan kosa kata dan mempunyai ide yang cemerlang. Orang lain akan mudah memahami tulisan, jika tulisan yang disajikan secara sistematis. ${ }^{11}$

\footnotetext{
${ }^{7}$ Wina Sanjaya, Strategi Pembelajaran: Berorientasi Standar Proses Pendidikan, Jakarta: Prenada Media Group, 2006, 112.

8 Munir, Pembelajaran Jarak Jauh Berbasis Teknologi Informasi dan Komunikasi, Bandung: Alfabeta. 2009, 181-182.

${ }^{9}$ Muhammad Sholih, Al-Maharat al-Lughawiyah. Saudi: Daru al-Andalus linnasyir al Rauzi, 1994, 205.

${ }^{10}$ Hermawan, Metodologi Pembelajaran 51.

${ }^{11}$ Halimatus Sa`diyah, dkk, Strategi Pembelajaran Bahasa Arab Penuh Inovasi dan Kontemporer, Malang: Nusantara Global Press, 2019, 21.
} 
Kitabah menjadi media untuk menyebarluaskan dan melestarikan ilmu pengetahuan dan informasi. ${ }^{12}$ Di dalam kitabah lah tergambar jelas lambanglambang yang membentuk fonem, kata, kalimat dan paraghraph yang menunjukkan pesan yang ingin disampaikan.

Kemampuan yang hendak dicapai dalam pembelajaran Bahasa Arab ada dua, yaitu kemampuan teknis dan kemampuan produksi (ibdai). Kemampuan teknis terkait dengan kemampuan untuk menulis Bahasa Arab dengan benar sesuai dengan kaidahnya, seperti kebenaran imla' (tulisan), qawaid (susunan), dan penggunaan alamat al-tarqim (tanda baca). Sedangkan kemampuan produksi terkait dengan kemampuan untuk mengungkapkan gagasan, perasaan dan ide dalam Bahasa Arab secara sistematis, logis dan benar. ${ }^{13}$

Tujuan pembelajaran Mahârah al-kitâbah akan tercapai jika kedua kemampuan tersebut diintegrasikan dalam proses pembelajaran. Diantara ketercapaian tersebut adalah: ${ }^{14}$

1. Adanya kebiasaan yang benar dalam menulis dengan Bahasa Arab

2. Munculnya deskripsi yang cermat dan tepat pada hal yang dilihat atau di alami.

3. Munculnya ide dan pikiran yang diekspresikan secara bebas

4. Adanya pembiasaan untuk memilih kosa kata dan kalimat yang sesuai dengan konteks kehidupan

5. Membantu memunculkan pikiran, gagasan, perasaan dan ide dalam ungkapan Bahasa Arab secara jelas, benar, berkesan dan imajinatif

6. Adanya kemampuan dalam menulis dengan Bahasa Arab secara cermat yang sesuai dengan konteks

Dalam proses pembelajarannya, Mahârah Kitabah memiliki beberapa tahapan mulai dari tahap pemula, menengah, dan lanjutan. Hal ini disesuaikan dengan kemampuan peserta dan kurikulum yang telah ditetapkan. Agar mahasiswa (peserta didik) mencapai tahap mahir, maka diperlukan tahapan

\footnotetext{
${ }^{12}$ Nurjamal Daeng, Terampil Berbahasa, Bandung: Alfabeta, 2011, 4.

${ }_{13}$ Abdul Hamid, Mengukur Kemampuan Bahasa Arab untuk Studi Islam, Malang: UIN -Maliki Press, 2013, 74.

${ }^{14}$ Ahmad Muradi, Pembelajaran Menulis Bahasa Arab dalam Perspektif Komunikatif, Jakarta: Kencana, 2015, 74.
} 
dalam belajar Mahârah al-kitâbah , antara lain: ${ }^{15}$

1. Tahap mencontoh. Dalam tahap ini, mahasiswa seringkali meremehkan karena mencontoh tulisan menjadi tahap yang sudah dilakukan. Tahapan ini adalah tahap awal dan dasar untuk melakukan praktek ketika mengenalkan materi.

2. Tahap reproduksi. Pada tahap ini mahasiswa (peserta didik) diajak menulis kata atau kalimat yang telah dipelajari secara lisan.

3. Tahap imla: Pada tahap ini, kemampuan pemahaman terhadap teks yang diperdengarkan dapat diukur, serta mahasiswa (peserta didik) dilatih untuk menyimak teks secara seksama.

4. Tahap Rekombinasi dan Transformasi adalah latihan menggabungkan kata sesuai kaidah nahwiyah dan mengubah bentuk kalimat sesuai dengan kaidah nahwiyah dan sharfiyah

5. Tahap insya muwajjah adalah diperuntukkan bagi mahasiswa (peserta didik) yang telah memiliki ratusan kosa kata dan konsep kebahasannya telah matang. Sehingga, mahasiswa di tahap ini disiapkan untuk berlatih menulis dengan menggunakan berbagai perubahan bentuk tata bahasa atau susunan bahasa yang telah didaptkan pada pembelajaran kalam, qiroah dan imla: Gradasi pembelajaran pada tahap ini dimulai dari kata, kalimat, satu paraghrap, berlanjut menjadi dua paraghrap dan begitu seterusnya. ${ }^{16}$ Sebagai contoh dari kegiatan pembelajaran kitabah al-muwajjah adalah mendeskripsikan gambar, membalas surat, merangkum dari sebuah teks dan menggabungkan kata atau kalimat yang terpisah. ${ }^{17}$

6. Tahap insya hurr adalah tahapan terakhir dari pembelajaran Mahârah alkitâbah . Pada tahap ini, mahasiswa (peserta didik) tetap dibawah bimbingan tetapi mempunyai kebebasan untuk memilih tema, pemilihan kosa kata dan tarakib yang digunakan dalam kitabah nya.

Selain tahapan-tahapan yang disebutkan di atas, dalam pembelajaran Mahârah al-kitâbah perlu memperhatikan prinsip-prinsip yang ada di dalamnya, yaitu: ${ }^{18}$

15 Wafa, Ahris Choiril. Problematika Pembelajaran Maharah al-Kitabah Siswa Kelas X MAN Tempel Sleman, Yogyakarta: 2014, 15-17.

${ }^{16}$ Abdul, Hamid, Pembelajaran Bahasa.........., 49-60.

17 Furqanul, dkk. Pengajaran Bahasa Komunikatif (Teori dan Praktek), Bandung: Remaja Rosda Karya: Tanpa Tahun, 31.

${ }^{18}$ Wahab, Pengembangan Strategi 45-46. 
1. Terdapat kejelasan pada tema dan ketentuan lainnya

2. Tema berasal dari kehidupan nyata atau pengalaman mahasiswa (peserta didik) Sesuai dengan alur pembelajaran insya .

3. Memiliki kemahiran dalam menulis alphabet (hijaiyah)

4. Mempunyai kemahiran mengeja huruf hijaiyyah, kata dan kalimat Bahasa Arab.

5. Serta memiliki kemahiran menyampaikan pikiran atau ide.

\section{Up date status Melalui Media Whatsapp}

Media dalam Bahasa latin disebut dengan medium, yaitu perantara sedangkan dalam Bahasa Arab disebut dengan wasilah, yaitu pengantar pesan dari pengirim kepada penerima pesan. ${ }^{19}$ Dari pendapat para pakar pendidikan, media pembelajaran diartikan sebagai berbagai alat yang dapat memberikan dorongan, rangsangan dan motivasi bagi peserta didik, sehingga menimbulkan keinginan untuk terus belajar. ${ }^{20}$ Disebutkan pula, bahwa media adalah sarana fsik untuk menyampaikan materi da nisi pembelajaran, berupa video, buku, film, dsb. ${ }^{21}$ Pendapat yang lain, media adalah sumber belajar yang digunakan untuk menyampaikan pesan pembelajaran. ${ }^{22}$

Jadi, media dalam pembelajaran menjadi sesuatu yang penting dalam penyampaian materi pelajaran. Dengan demikian informasi akan lebih cepat dan mudah untuk diproses oleh peserta didik tanpa harus melalui prose yang panjang yang akan menjadikannya menjadi jenuh, apalagi dalam proses pembelajaran bahasa, dimana peserta didik dibekali keterampilan bahasa dengan cara berlatih secara kontinyu adalah membosankan, sehingga keadaan media sangat dibutuhkan. ${ }^{23}$

Dalam pembelajaran, media menjadi alat yang mempermudah proses pembelajaran. Media dapat menyederhanakan bagian-bagian pembahasan yang

\footnotetext{
${ }^{19}$ M. Abdul Hamid dkk Pembelajaran Bahasa Arab Pendekatan, Metode, Strategi, Materi Dan Media, Malang: UIN Malang Press, 2008, 168.

${ }^{20}$ Maksudin, Media Pembelajaran Bahasa Arab Dalam Jurnal Al-`Arabiyah. Vol. 2, Tahun 2006, 2.

${ }^{21}$ Imam Asrori, Media Pembelajaran Bahasa Arab, Malang: CV Bintang Sejahtera, 2015, 3.

22 Tejo Nurseto, Membuat Media Pembelajaran yang Menarik, (UNY Jurnal Ekonomi \& Pendidikan, Volume 8 Nomor 1, April 2011, 21.

23 Umi Mahmudah dan Abdul Wahab Rosyidi, Active Learning Dalam Pembelajaran Bahasa Arab, Malang: UIN Malang Press, 2008, 99.
} 
rumit. Fungsi media sebagai alat bantu akan memberikan peningkatan durasi belajar bagi peserta didik. ${ }^{24}$ Meskipun demikian, pemilihan dan penggunaan media dalam pembelajaran harus tetap mengacu pada tujuan pembelajaran yang akan dicapai, agar media bukan menjadi penghambat dari efektifitas dan efisiensi dari tujuan pembelajaran. ${ }^{25}$ Media pembelajaran juga merupakan wahana informasi yang betujuan terjadinya proses belajar pada diri peserta didik sehingga akan terjadi perubahan perilaku, baik berupa kognitif (pengetahuan), efektif (sikap), psikomotor (keterampilan).

Di zaman yang sudah serba digital, maka media pembelajaran dapat didapatkan dengan memanfaatkan berbagai fasilitas digital yang ada di sekitar mahasiswa (peserta didik). Pengajar bertugas untuk memilih media yang tepat untuk digunakan sesuai dengan kebutuhan pembelajaran. ${ }^{26}$ Penyerapan materi, penerimaan materi yang lebih banyak dan peningkatan performance dapat dibantu dengan pembelajaran yang kreatif dan inovatif yang dilakukan dengan media. Pembelajaran dengan menggunakan media akan menghasilkan prosentase pada aspek kognitif, afektif dan psikomotor lebih besar dari pada pembelajaran yang hanya menggunakan indera. ${ }^{27}$

Media social menjadi kebutuhan primer di era digital. Kehadiran media social mempermudah jalinan komunikasi tanpa adanya batas ruang dan waktu serta mendapatkan berbagai informasi dari belahan dunia. Beberapa media social yang dipergunakan oleh banyak khalayak adalah Facebook, WhatsApp, Instagram, dan Google.com. ${ }^{28}$ Tidak heran jika, media social juga dapat menjadi bagian dari media-media lainnya yang dapat dipergunakan untuk mempermudah pembelajaran.

Kecanggihan internet dan media social menjadikan whatsapp sebagai salah satu pilihan yang digunakan dalam pembelajaran. Whatsapp dapat digunaan melalui smartphone dan fitur-fitur yang terdapat didalamnya menjadikannya

\footnotetext{
${ }^{24}$ Jepri Nugrawiyati, Media Audio-Visual Dalam Pembelajaran Bahasa Arab, El-Wasathiya: Jurnal Studi Agama. Volume 6, Nomor 1, Juni 2018; p-ISSN 2338-9648, e-ISSN: 2527631X, 2018, 100

${ }^{25}$ Syaiful Bahri Djamarah, Strategi BelajarMengajar, Jakarta: Rineka Cipta, 2010, 120.

26 M. Abdul Hamid, Pembelajaran Bahasa .............., 171.

27 Soenjoyo Dirjo Soemarto, Bahasa Arab dan Metode Pengajarannya: Beberapa Pokok Pikiran. Yogyakarta: Pustaka Pelajar, 2003, 75.

${ }^{28}$ Wahyuni Januarti Drakel' Maria Heny, Perilaku Mahasiswa Dalam Menggunakan Media Sosialdi Universitas Sam Ratulangi Manado Dalam Jurnal: HOLISTIK. Tahun XI No. 21A / Januari - Juni, 2018.
} 
familiar di berbagai kalangan, termasuk di kalangan mahasiswa. Kebutuhan terhadap jarngan internet terus mengalami peningkatan di Indonesia. Dengan layanan whatsapp, dapat memperoleh kemudahan, seperti mengirim gambar, chatting, berbagi video, berbagi informasi, mengirim dokumen atau foto, dan update status. ${ }^{29}$

Update status dapat digunakan untuk mengirim tulisan tanpa gambar atau gambar saja atau gambar dilengkapi dengan tulisan. Dengan tulisan, gambar atau gambar beserta tulisan yang diunggah di status whatsapp, maka setiap orang yang menyimpan nomer whatsapp pengirim dan pengirim menyimpan nomer whatsapp orang lain tersebut, maka status yang diupload akan dibaca atau dilihat oleh orang yang menyimpan nomer whatsapp pengirim. Sehingga, dalam pembelajaran, termasuk Mahârah al-kitâbah dapat menggunakan update status di media whatsapp agar terjadi latihan yang kontinyu.

\section{Implementasi Mahârah al-kitâbah melalui update status pada Media Whatsapp}

Belajar dengan menggunakan media akan dapat membantu proses pembelajaran itu sendiri. Begitu pula dengan pembelajaran Bahasa Arab, khususnya Mahârah al-kitâbah. Pembelajaran Mahârah al-kitâbah melalui update status pada media whatsapp dalam mengimplementasinya dilakukan tiga langkah.

\section{Pertama: tahap persiapan}

Pada tahap ini dosen memastikan bahwa setiap mahasiswa mempunyai whatsapp dan smart phone telah terinstall dengan keyboard Arab dan mahasiswa mampu menggunakannya.

1. Dosen menyampaikan tujuan pembelajaran yang akan dicapai.

2. Dosen memiliki semua nomer whatsapp mahasiswa yang diampu atau dilatih Mahârah kitabah nya.

29 Aji dan Singgih Hutomo, Pengembangan Aplikasi Layanan Pesan Instan Whatsapp Sebagai Sumber Belajar Mandiri Untuk Meningkatkan Motivasi Dan Hasil Belajar Fisika Materi Pokok Efek Rumah Kaca Peserta Didik Kelas Xi Sma N 1 Purwokerto. Skripsi. Yogyakarta: Universitas Negeri Yogyakarta, 2018, 5. 
3. Dilakukan kesepakatan bersama tentang ketentuan waktu dan jam pengiriman penulisan kalimat berbahasa Arab di update status, misalkan seminggu sekali, dan seterusnya.

4. Disampaikan pula update status harus dengan tema yang disepakati, misalkan tema al-madinah, dan seterusnya.

5. Ditentukan pula jumlah kalimat yang dikirim melalui update status di whatsapp.

\section{Kedua: tahap pelaksanaan}

Pada tahap ini, mahasiswa menulis kalimat berbahasa Arab sesuai dengan tema yang telah disepakati dan ditentukan. Mahasiswa dapat mengirimkan tulisan tersebut sebagai status baru mereka di whatsapp. Update status tidak hanya dapat berupa tulisan, tetapi juga dapat dilengkapi dengan gambar atau foto yang sessuai dengan tema. Sehingga, mahasiswa dituntut untuk kreatif.

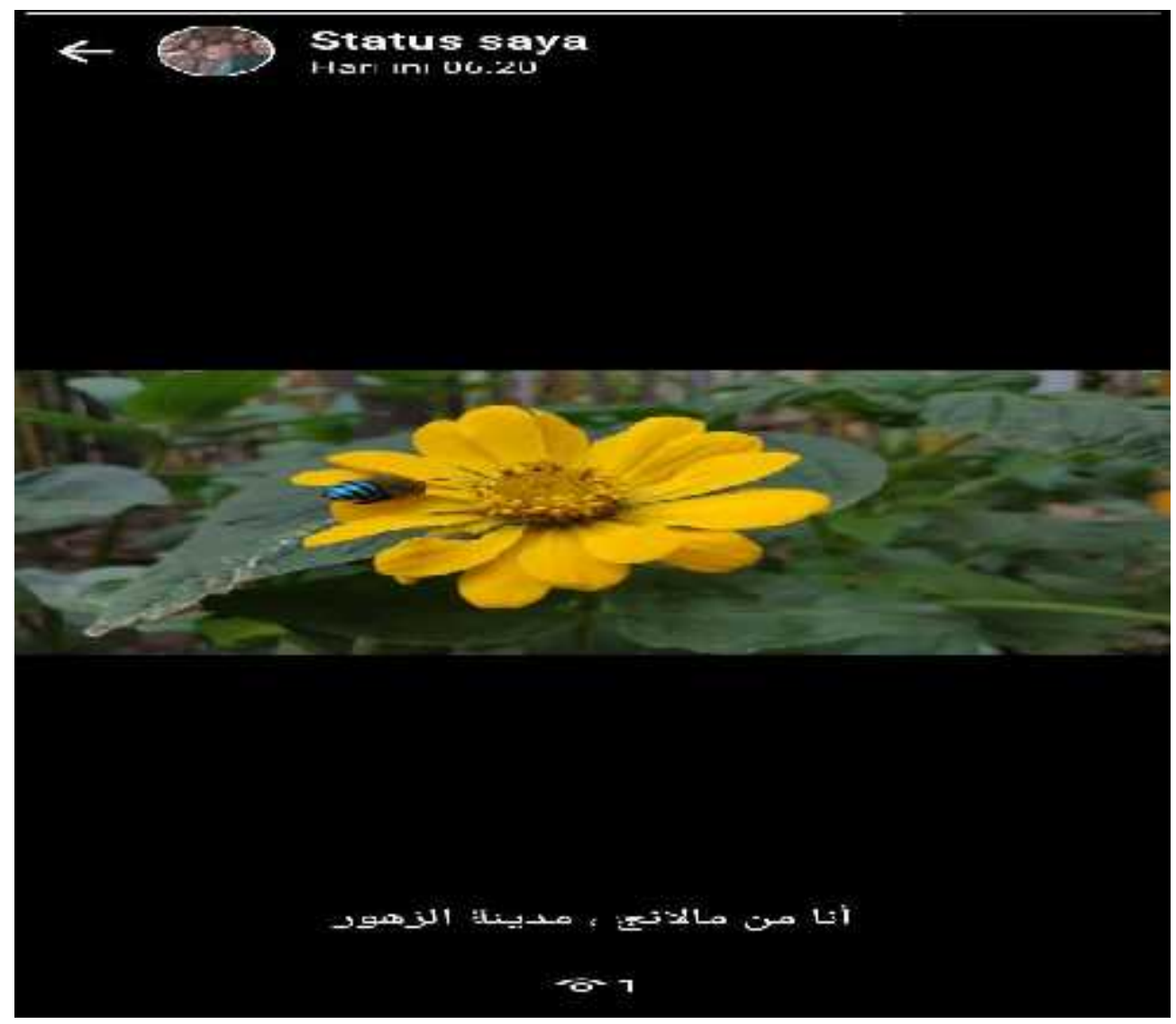

Gambar 1: Mahârah al-kitâbah dengan Update Status Mahasiswa, tema: "At-ta`aruf" 


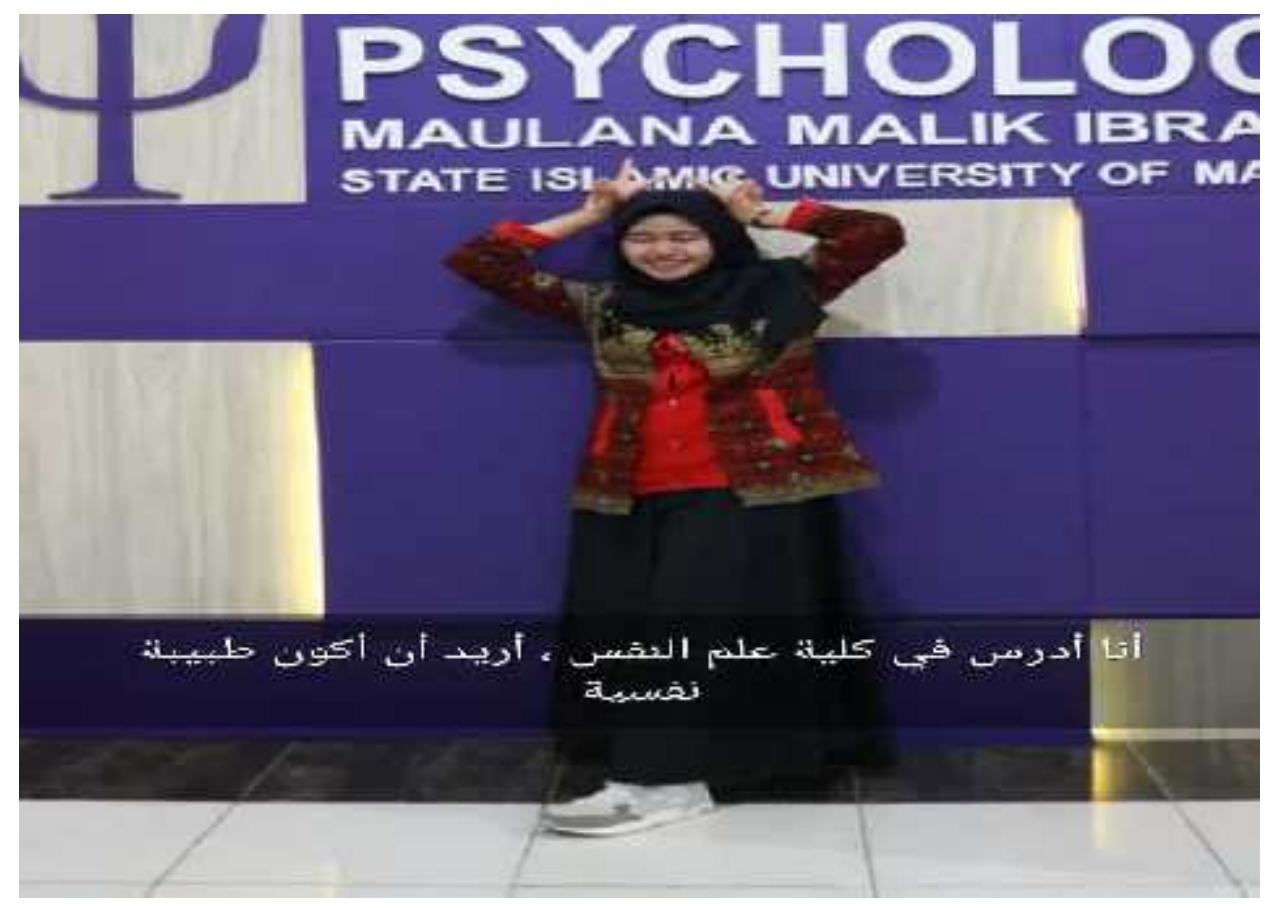

Gambar 2: Mahârah al-kitâbah dengan Update Status Mahasiswa, tema: "ad-dirasah"

\section{Ketiga: tahap Penutup}

Di tahap ketiga ini, dosen melakukan evaluasi dan penilaian terhadap semua kitabah kalimat mahasiswa yang telah di kirim melalui update stutus di whatsapp. Dosen memberikan saran agar membenarkan tulisan bagi mahasiswa yang masih mengalami salah dalam penulisan kalimat. Setelah diberikan respon oleh dosen, maka mahasiswa harus melakukan perbaikan dan menulis kalimat yang benar (kembali) pada update status nya dan menghapus status sebelumnya. Begitu seterusnya sampai mahasiswa melakukan kitabah kalimat dengan benar dan sesuai dengan kaidah Bahasa Arab. kegiatan ini dilakukan secara wapri (whatsapp pribadi) atau tidak melalui grup WA.

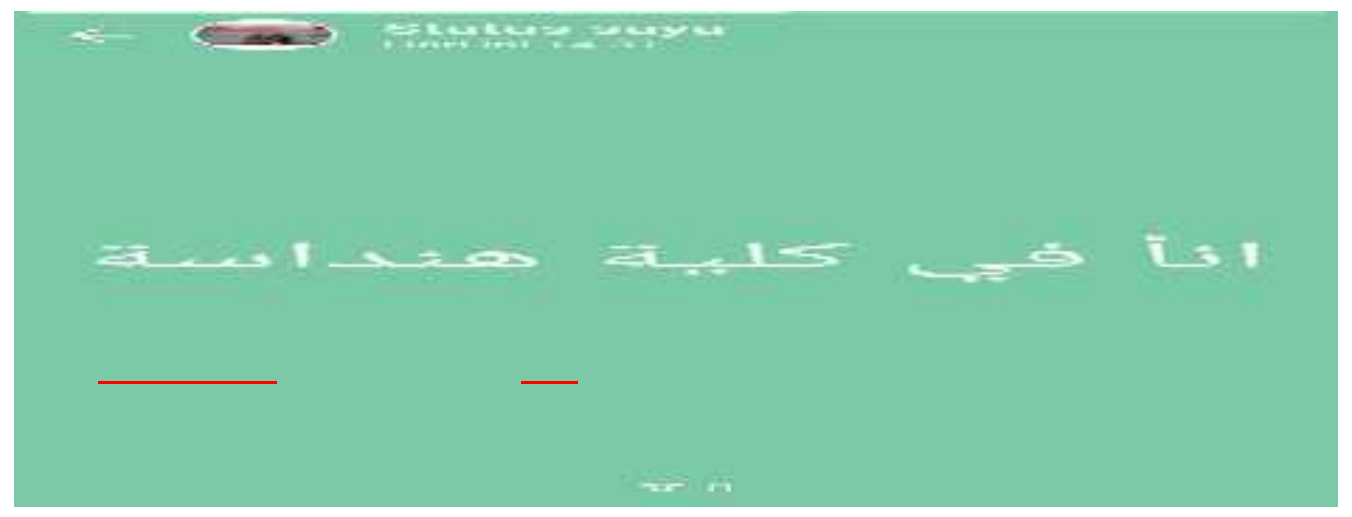

Gambar 3: Koreksi dari dosen terhadap Update Status Mahasiswa Mahârah al-kitâbah pada tema "ad-dirasah" 
Implementasi pembelajaran Mahârah al-kitâbah melalui update status pada media whatsapp mengandung kelebihan dan kekurangan. Diantara kelebihannya adalah melatih mahasiswa untuk selalu melakukan latihanlatihan yang kontinyu dan langsung mendapatkan respon dari dosen tentang kesalahan penulisan yang dilakukan. Sehingga, Arab tanpa disadari mahasiswa semakin mahir untuk menulis Bahasa. Serta, kitâbah dengan update status berbahasa Arab dapat membantu mahasiswa menyebarkan Bahasa Arab, meskipun secara tidak langsung kepada orang lain, yaitu kepada orang-orang yang telah menyimpan nomer whatsapp mahasiswa tersebut.

Kekurangan dari Implementasi pembelajaran Mahârah al-kitâbah melalui update status pada media whatsapp, diantaranya membutuhkan waktu yang lebih lama dalam evaluasi dan koreksi tulisan mahasiswa, karena harus diteliti satu persatu. Mahasiswa perlu diingatkan bahwa tulisan yang dikirim pada status harus berbeda dengan tulisan temannya agar mereka terbiasa untuk berkreasi sendiri. Kendala berikutnya adalah selalu harus diingatkan pada mahasiswa akan adanya jadwal atau waktu untuk pengiriman update status.

\section{E. KESIMPULAN}

Pembelajaran Mahârah al-kitâbah bagi mahasiswa menjad hal yang perlu dilakukan secara terus-menerus. Agar pembelajaran dapat menarik, maka penggunaan media social dapat menjadi salah satu alternative dalam pembelajaran tersebut. Salah satunya adalah penggunaan whatssapp yang didalamnya terdapat fitur update status. Dengan tetap berpedoman pada tujuan pembelajaran kitabah yang akan dicapai, mahasiswa berlatih menulis kalimat Bahasa Arab secara kontinyu melalui aktifitas dan media tersebut.

Tema-tema yang dituliskan juga disesuaikan dengan target pembelajaran. Tentu, implementasi update status pada whatsapp pada pembelajaran Mahârah al-kitâbah ini memiliki kelebihan dan kekurangan. Meskipun demikian, kekurangan yang ada dalam implementasi tersebut tidaklah menjadi penghalang utama dalam peningkatan pembelajaran Mahârah al-kitâbah , terutama bagi mahasiswa non-Arab di zaman digital ini. 


\section{DAFTAR PUSTAKA}

Furqanul, dkk. Pengajaran Bahasa Komunikatif (Teori dan Praktek), Remaja Rosda Karya: Bandung.

Oemar Hamalik, Media Pendidikan, Bandung: PT.Citra Andily Bakti, 1989.

Abdul Hamid, Mengukur Kemampuan Bahasa Arab untuk Studi Islam, Malang:

UIN-Maliki Press. 2013.

Abdul Hamid, dkk.. Pembelajaran Bahasa Arab. Malang: UIN Malang Press, 2008. Acep Hermawan, Metodelogi Pembelajaran Bahasa Arab, Bandung: Rosda, 2011.

Imam Asrori, Media Pembelajaran Bahasa Arab, Malang: CV Bintang Sejahtera, 2015.

Jepri Nugrawiyati, Media Audio-Visual Dalam Pembelajaran Bahasa Arab Dalam Jurnal El-Wasathiya: Jurnal Studi Agama. Volume 6, Nomor 1, Juni 2018; p-ISSN 2338-9648, e-ISSN: 2527631X,

Daeng Nurjamal, Terampil Berbahasa, Bandung: Alfabeta, 2011.

Maksudin, Media Pembelajaran Bahasa Arab. Jurnal Al-`Arabiyah. Vol. 2. 2006

Ahmad Muradi, Pembelajaran Menulis Bahasa Arab dalam Perspektif Komunikatif, Jakarta: Kencana, 2015.

Sadat, A. (2017). LINGKUNGAN BAHASA SEBAGAI MEDIA PEMBELAJARAN BAHASA ARAB (Ikhtiar membangun Pembelajaran Yang Efektif dan Produktif). AL-AF'IDAH: Jurnal Pendidikan Bahasa Arab dan Pengajarannya, 1(1), 7.

Wina Sanjaya, Strategi Pembelajaran: Berorientasi Standar Proses Pendidikan, Jakarta: Prenadamedia Group, 2006.

H Sa`diyah, Upaya Menumbuhkan Self-Confidence Berbicara Bahasa Arab Mahasiswa Melalui Grup Whatsapp dalam jurnal Al Mi’yar: Jurnal Ilmiah Pembelajaran Bahasa Arab dan Kebahasaaraban, 2(2), 149.

Halimatus Sa`diyah, dkk Strategi Pembelajaran Bahasa Arab Penuh Inovasi dan Kontemporer. Malang: Nusantara Global Press, 2019.

Muhammad Sholih, Al-Maharat al-Lughawiyah, Saudi: Daru al-Andalus linnasyir al Rauzi', 1994.

Singgih Hutomo Aji. Pengembangan Aplikasi Layanan Pesan Instan Whatsapp Sebagai Sumber Belajar Mandiri Untuk Meningkatkan Motivasi Dan Hasil Belajar Fisika Materi Pokok Efek Rumah Kaca Peserta Didik Kelas Xi Sma N 1 Purwokerto. Skripsi. Yogyakarta: Universitas Negeri Yogyakarta, 2018.

Soenjoyo Dirjo Soemarto. Bahasa Arab dan Metode Pengajarannya: Beberapa Pokok Pikiran. Yogyakarta: Pustaka Pelajar, 2003.

Syaiful Bahri Djamarah, Strategi BelajarMengajar, Jakarta: Rineka Cipta, 2010.

Tejo Nurseto, Membuat Media Pembelajaran Yang Menarik, UNY Jurnal Ekonomi \& Pendidikan, Volume 8 Nomor 1, 2011. 
Munir, Perencanaan Sistem Pembelajaran Bahasa Arab: Teori dan Praktik, Jakarta: Kencana, 2017.

Umi Mahmudah dan Abdul Wahab Rosyidi, Active Learning Dalam Pembelajaran Bahasa Arab, Malang: UIN Malang Press, 2008.

Ahris Choiril Wafa, Problematika Pembelajaran Mahârah al-Kitâbah Siswa Kelas X MAN Tempel Sleman, Yogyakarta, 2014.

Abdullah Wahab dkk, Pengembangan Strategi Pembelajaran Bahasa Arab dengan Teori Mikro Robert Mill Gagne di Madrasah Tsanawiyah Al Maarif 01 Singosari Malang, 2016.

Wahyuni Januarti Drakel' Maria Heny, Perilaku Mahasiswa Dalam Menggunakan Media Sosialdi Universitas Sam Ratulangi Manado Dalam Jurnal: Holistik, Tahun XI No. 21A / Januari - Juni, 2018. 